\title{
Leer los hospitales en tiempos de pandemia: el profesional sanitario, protagonista de excepción'
}

\author{
Reading Hospitals in Pandemic Times - Health Professionals, \\ Main Emergency Actors
}

\author{
GABRIEL AGUILERA MANRIQUE \\ Universidad de Almería \\ España \\ gaguiler@ual.es
}

(Recibido:II/O5/2O2O; aceptado: $16 / 05 / 2020$ )

Resumen. Los últimos meses hemos vivido una circunstancia de excepción en nuestro país ante la pandemia provocada por la COVID-19. Ha sido un tiempo de profunda preocupación que nos ha mantenido sobrecogidos ante las cifras de afectados y fallecidos, sin precedente. El confinamiento nos ha hecho reflexionar sobre el papel del principal agente social que ha luchado cara a cara con este virus: el conjunto de trabajadores de la sanidad española. Mientras la población general se ha quedado en casa como medida de contención, los hospitales y centros de salud son el frente abierto donde muchos hombres y mujeres con batas blancas, verdes y azules han puesto la vida de los demás por encima de la suya. Así, con las páginas siguientes queremos homenajear a todo un colectivo que ha demostrado la mayor generosidad y compromiso ciudadano, más allá de lo que supone el cumplimiento estricto de sus funciones.

Palabras clave: lectura de una pandemia; personal sanitario; COVID-I9; compromiso social.
Abstract. During the last months, Spain has experienced emergency circumstances provoked by the COVID-19 pandemic. It has been a time of deep concern whose unprecedented number of affected and deceased people have proved to be overwhelming. The confinement has forced us to reflect on the role of the main social agent; all the workers of the Spanish healthcare system who have fought face to face against the virus. While the general populations has stayed at home as a measure of containment, hospitals and health clinics have been the open front where many men and women wearing white, green, and blue uniforms have put other's lives above their own. These pages attempt to pay tribute to the healthcare professionals that have shown the biggest generosity and compromise toward citizens, beyond just the strict observations of their duties.

Keywords: reading during a pandemic; health professionals; COVID-19; social commitment.

\footnotetext{
I Para citar este artículo:Aguilera Manrique, G. (202O). Leer los hospitales en tiempos de pandemia: el profesional sanitario, protagonista de excepción. Alabe 22 . [www.revistaalabe.com]

DOI: IO.I5645/Alabe2O2O.22.I2
} 
La salud tiene actualmente un protagonismo inédito. La Organización Mundial de la Salud (OMS) ya la definió, el siglo pasado, como el estado de bienestar físico, mental y social completo y no solamente la ausencia de enfermedad. Definición, desfasada, que esperamos actualice la OMS puesto que hay nuevos condicionantes en la población como, por ejemplo, la presencia de las enfermedades crónicas que no contempla la actual definición.

Los contemporáneos no recuerdan otro episodio como el actual, con la pandemia de la COVID-ı9, que amenazara la salud de la población. En la historia reciente del último siglo, han existido eventos que desafiaron la salud de la población, la pandemia de gripe (mal llamada) española del r9ı8, la enfermedad del Ébola y los brotes del SARS (síndrome respiratorio agudo grave). Estas últimas enfermedades siempre se han visto en la lejanía, afectaban a países subdesarrollados y formaban parte de unos pocos minutos en los informativos. La asociación ingenua era relacionar epidemias con pobreza mundial y se ha comprobado la inexactitud de esta relación. En un mundo globalizado es un error creer que hay barreras infranqueables y los niveles de alerta se han cuestionado por su fragilidad, ejecución mejorable y extemporaneidad.

La atención a la salud se contempla desde el origen de la civilización humana, pero fue en la época griega y romana donde se sentaron las bases de la medicina occidental. Hipócrates o Galeno fueron personajes relevantes en el campo de la medicina occidental como lo fue Florence Nightingale en el campo de la enfermería. Médicos y enfermeras, profesionales sanitarios protagonistas, sin duda, de esta pandemia actual.

Este año, 2020 del COVID, se conmemora el 200 aniversario del nacimiento de Nightingale (I820-І9Іо), considerada la precursora de la Enfermería moderna. Entre I853 y I856 tuvo lugar la llamada guerra de Crimea, donde muchos soldados fueron heridos y murieron porque no había nadie para tratarles. En ese momento, una enfermera llamada Florence Nightingale se ofreció como voluntaria para ir al campo de batalla a cuidar de los soldados heridos y salvar vidas. Además, reformó los servicios de atención médica y de enfermería. Casualidades del destino, el año de la conmemoración del nacimiento de Nightingale coincide con la pandemia actual y en la que Nightingale, en aquella época, fue abanderada de aplicar los principios de salud pública. Con motivo de este aniversario, se ha creado este año el movimiento Nursing Now que persigue mayor inversión en la educación, desarrollo profesional y reconocimiento de la enfermera que, este año con motivo de la desgraciada pandemia, lo han tenido las enfermeras y todos los profesionales sanitarios.

La formación del profesional sanitario es excelente. El acceso del estudiante, motivado para realizar esta formación, tiene la mayor nota de corte de la universidad y con expedientes sobresalientes. El diseño de carreras profesionalizantes en salud tienen en su plan de estudios casi la mitad de sus créditos de formación práctica. Supone estar en una situación privilegiada, en relación a otras carreras, con un alto grado de preparación en competencias de conocimientos, habilidades y actitudinales. Un estudiante está realizando sus prácticas en un hospital, por ejemplo, en el mes de junio y al mes siguiente 
finaliza sus estudios y está contratado sabiendo perfectamente realizar su trabajo. Las prácticas, supervisadas con tutores clínicos, se realizan en el ámbito asistencial real en el que van después a trabajar, situación privilegiada sin duda.

Con la implantación de la convergencia europea de educación superior, con sus luces y sombras, se conoció mejor la realidad del profesional sanitario europeo. Actualmente, el profesional español tiene unos niveles competenciales excelentes muy demandados por el mercado europeo.

Un punto destacable en la formación es el aspecto actitudinal, muy importante en el desarrollo competencial de la relación con la persona. El profesional sanitario debe tener sensibilidad para detectar las necesidades de la persona, relación de ayuda y empatía con la persona que cuida. La responsabilidad de tratar con personas en situación vulnerable y con necesidades, convierten a este profesional en una persona comprometida con la salud de los demás, priorizando sobre su propia salud, como se ha visto en esta pandemia que han trabajado sin protección, contagiándose y perdiendo la vida. La llamada vocación de estos profesionales, es decir realizar el trabajo que quiero, combate al miedo de ser contagiados. Son trabajadores diferentes, generosos, responsables, sensibles, comprometidos... con los demás. Imagínense una huelga en la pandemia, como pasa en otros sectores, nadie lo comprendería, pero son trabajadores también, como ellos reconocen y no solo héroes, como los denominan ahora.

Cualquier aspecto de la vida podría relativizarse, la salud no. La sociedad actualmente lo ha reconocido en esta situación. La amenaza de esta pandemia cambiara diferentes aspectos de nuestras vidas, las relaciones sociales y ese concepto nuevo de "distanciamiento social”, la cercanía de un abrazo, de un saludo con besos en las mejillas... el calor del sur de Europa desaparece para acercarse al frío nórdico, llegaremos a un estadio intermedio en que prevalezca la seguridad, pero no eliminemos nuestra cercanía emocional y física. Queda pendiente si sabremos gestionar el miedo al contagio porque lavarnos las manos, sí parece que lo hemos aprendido.

La sociedad ha cambiado la visión que se tenía sobre el profesional sanitario o quizás se ha hecho más visible. Unos profesionales que siempre han estado a nuestro lado, pero muchas veces no se ha valorado lo suficiente la necesidad que tiene el mundo de ellos. Son ellos los que escuchan el primer llanto de los bebés recién nacidos y son testigos del último aliento del paciente al final de su vida. Están presentes en algunos de los momentos más preciados de la vida al igual que en algunos de los más trágicos.

Los mismos profesionales sanitarios ha reconocido que no son héroes, simplemente hacen su trabajo por el que estudiaron y que les llena y satisface. Un último reconocimiento ha sido el del artista británico Banksy en su nueva obra, en ella, un simple niño está jugando con sus muñecos. Un pequeño ciudadano que también ha vivido y se ha enfrentado a este episodio de la historia moderna está únicamente entreteniéndose con sus juguetes de superhéroes y, tras haber sido consciente que la lucha estaba en manos de los que nos curaban y cuidaban en los centros sanitarios, elige como superhéroe a una enfermera. Esta enfermera, representada como aquellas de la Cruz Roja que sanaron a un 
mundo en guerra, se convierte en el héroe natural para los niños. El protagonista de esta historia deja de lado a Spiderman y Batman y selecciona a la que él elige como verdadera heroína.

Finalmente, el mejor homenaje y reconocimiento que se puede hacer, a todos los profesionales sanitarios en relación a su trabajo en la pandemia, es trascribir lo que manifiestan, todo un lujo:

"Nunca habíamos imaginado algo así"

"Me resulta muy duro que no puedan estar con su familia"

"Muchos días lloro de impotencia y de rabia"

"Trabajamos más unidos que siempre para parar este virus"

"Estando nosotras, ningún paciente morirá solo"

"Nosotras les estamos cogiendo la mano día a día"

"He llorado más en esta semana que en i8 años de profesión"

"Solo podemos salir una vez de la unidad en 7 horas"

"No podemos tocarnos, pero a través de la mirada nos estamos abrazando"

"Los verdaderos héroes están siendo los pacientes"

"Los aplausos nos ayudan a seguir luchando, esto es muy duro"

"Lo peor es no ver a mis hijos para no contagiarlos" 